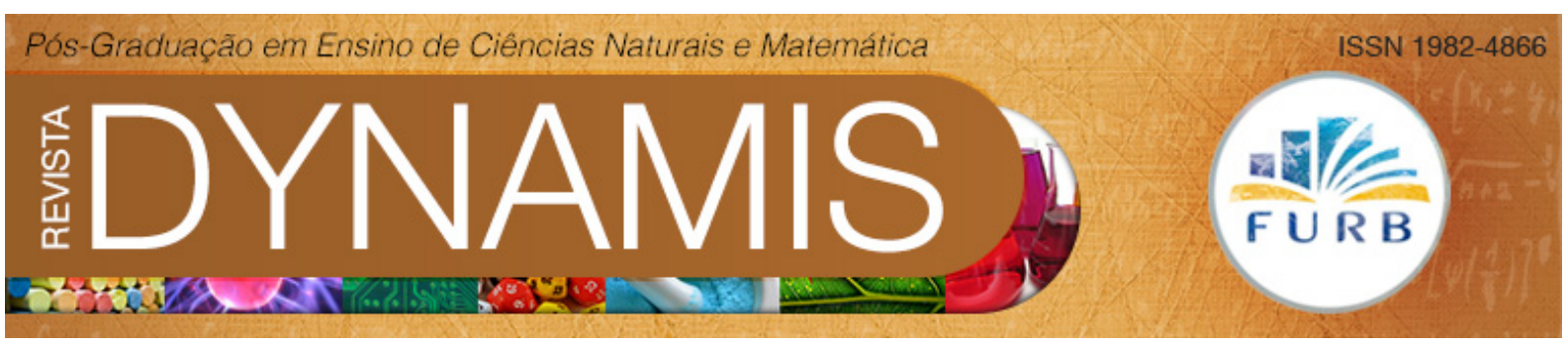

\title{
Investigação de ferramentas e métodos de ensino de circuitos de corrente alternada para curso introdutório de eletrotécnica
}

Research Tools and Methods of Teaching of Alternating Current Circuits for Introductory Course Electrotechnical

Ilse Abegg

Universidade Federal de Santa Maria

ilse.abegg@ufsm.br

Diego Berlezi Ramos

Universidade Federal do Pampa - Campus Alegrete

diegoramos@unipampa.edu.br 


\section{Resumo}

Este estudo analisa a aplicação de recursos tecnológicos de ensino para avaliar a potencialidade explanativa do tópico Corrente Alternada na disciplina de Eletrotécnica do curso Técnico em Eletromecânica do Colégio Técnico Industrial de Santa Maria. Procura-se avaliar as ferramentas de ensino usadas para a percepção dos alunos iniciantes no tópico corrente alternada, verificar o impacto da introdução de variadas técnicas/ferramentas e observar a adaptação do professor e dos estudantes às ferramentas/metodologias baseadas em recursos transmidiáticos. A pesquisa se deu por meio de observações feitas em uma turma e os resultados obtidos são interpretados e apresentados ao longo deste artigo.

Palavras-chave: Educação profissional, eletrotécnica, ferramentas de ensino.

\section{Abstract}

This study analyzes the application of technological resources for teaching explanativa evaluate the potential of alternating current topic in the discipline of Electrical Electromechanical Technician Course College of Technical Industrial de Santa Maria. It seeks to assess the teaching tools used for the perception of beginners on the topic AC, check the impact of the introduction of various techniques / tools and observe the adaptation of the teacher and students to the tools / methodologies based on transmidiáticos resources. The research was done through observations made in a class and the results are interpreted and presented throughout this article.

Keywods: Professional education, electrical engineering, teaching tools. 


\section{Introdução}

Durante muitas décadas as transferências didáticas nos cursos de eletrotécnica se deram, principalmente, por meio de recursos pedagógicos estáticos e em aulas baseadas em metodologias dialógico-expositivas. No entanto, alguns elementos dos currículos escolares dos cursos técnicos sofriam demasiadamente, devido às dificuldades de abstração necessárias e requeridas para entendimento, por parte dos alunos, dos conteúdos apresentados.

Contudo, nos últimos anos, e principalmente, ao longo da última década, o advento de novas ferramentas de ensino e a penetração dos recursos transmidiáticos, permitiram aos docentes, a inserção de novos recursos pedagógicos a serem utilizados em sala de aula. Isso permitiu conduzir as aulas a novos e diferentes níveis de extrapolação, simplificando de forma significativa a exposição de diversos elementos pertinentes à docência de disciplinas de nível técnico.

Neste contexto, uma das disciplinas mais frequentes nos currículos escolares de cursos técnicos, a cadeira de Eletrotécnica, pode ser assumida como uma das mais favorecidas pela modernização e atualização dos processos de ensino-aprendizagem.

A disciplina de Eletrotécnica, em geral, sempre foi motivo de temor para os estudantes pelo fato de representar, de fato, os primeiros contatos com os aspectos teóricos da área da física correlacionada à eletricidade. Em vias de sua existência, muitas vezes, esta disciplina apresenta aos alunos aspectos teóricos das ciências exatas básicas, tais como física, matemática e química de forma bastante antecipada em relação àquela em que estes conteúdos são ministrados em cursos de ensino médio tradicionais, não-profissionalizantes. Os problemas decorrentes deste avanço solicitado dos estudantes acaba por ser mais acentuado em cursos integrados, conduzidos ao longo dos estágios regulares do ensino médio.

Dessa forma, por necessidades curriculares e de estabelecimento de conhecimentos a respeito da grande área da eletricidade, torna-se por diversas vezes, deveras desafiador ao professor a introdução destes conteúdos aos alunos. Deve-se considerar também que é necessário chocar os discentes com tópicos que dificilmente seriam vistos em seus períodos regulares ou com muito menos rigorosidade.

Neste contexto, um elemento da disciplina de Eletrotécnica se destaca em termos de dificuldade no aprendizado: o estudo de circuitos elétricos de corrente alternada.

A apresentação de circuitos de corrente alternada ao estudante, na maioria das vezes implica em um aumentado grau de dificuldade, em face aos diversos elementos do aprendizado que devem ser processados simultaneamente de forma que o entendimento deste conteúdo possa ser adequadamente apropriado pelo estudante. Em geral, elementos matemáticos, tais como números complexos, conceitos de geometria e noções de grandezas fatoriais devem ser processadas em uníssono com conhecimentos da física mais avançada, tais como leis do eletromagnetismo, produção de energia elétrica, dentre outros.

De forma grandemente positiva, observa-se que a inclusão de recursos de mídia vídeos ilustrativos, simuladores de circuitos, softwares especializados, dentre outros recursos - podem flexibilizar os processos de ensino-aprendizagem tornando estes mais fluídos para o estudante.

Observa-se que a introdução de recursos tecnológicos em sala de aula permite um rompimento com antigas metodologias ortodoxas de ensino, baseadas em uma dialética mais "purista" e formal, conferindo aos professores, além de subterfúgios didáticos adicionais, novos formatos a serem abordados permitindo um favorecimento e o acréscimo de diversos 
graus de liberdade no que tange ao ensino das disciplinas correlatas aos conteúdos técnicos solicitados pelos cursos correspondentes de ensino profissionalizante.

Acredita-se que a utilização de tais recursos tecnológicos possa permitir aos alunos uma absorção mais adequada dos pré-requisitos técnico-teóricos necessários para o desenvolvimento de seu aprendizado ao longo do curso formativo profissional.

Para tanto, neste trabalho, será investigada a introdução de conteúdos técnico-teóricos referentes ao ensino inicial do tópico referente às correntes alternadas por meio da utilização de diferentes ferramentas de mídia a um grupo de alunos. Buscar-se-á observar como os estudantes aceitam diferentes ferramentas e como os mesmos recepcionam este ferramental do ponto de vista potencializante do aprendizado. A avaliação deste estudo se dará no próprio ambiente de sala de aula onde será conduzida a apresentação aos alunos dos recursos de mídia integrados. Dessa forma, poder-se-á elaborar uma avaliação a respeito de qual das técnicas surte mais efeito para ministrar as aulas introdutórias de circuitos de corrente alternada, por intermédio da observação dos alunos frente a proposição de problemas referentes a exercícios e suas diferentes formas de resolução por meio das ferramentas oferecidas aos estudantes.

Ao final do trabalho, acredita-se na possibilidade de se poder compilar uma síntese a respeito das ferramentas mais adequadas e quais seriam as estratégias mais interessantes para o desenvolvimento do tópico referente a circuitos de correntes alternadas em turmas do curso de eletrotécnica profissionalizante.

Nas seções a seguir é descrito o processo de pesquisa na área de estudo, apresentando a questão de pesquisa, hipótese e objetivos, referencial teórico, caminho metodológico a ser desenvolvido, bem como o planejamento das etapas necessárias para a execução de uma pesquisa, desde o projeto até sua socialização.

\section{Referencial teórico}

Conforme demonstrado por Costa (2008), há uma preocupação bastante intensa sobre o aprendizado dos tópicos referentes a circuitos elétricos entre os alunos de ensino médio. É observado que, de uma população de 300 alunos de universidades públicas brasileiras, apenas uma pequena parte $(15 \%)$ adquiriu o conhecimento conceitual suficiente para poderem analisar circuitos, sem a necessidade de fazer cálculos.

Em Ferreira (2009) são apresentadas algumas estratégias para aprimorar o ensino de circuitos elétricos em cursos de ensino médio. Neste trabalho, apresentam-se possibilidades para o desenvolvimento de circuitos elétricos entre alunos do ensino médio, com foco na disciplina de Física. Com experimentações, tanto reais como virtuais, chega-se ao conceito de Potência Elétrica. Assim, trata-se a inclusão de experimentos virtuais específicos, previamente selecionados por critérios bem definidos, como uma ferramenta que pode se somar ao material distribuído aos professores da rede pública.

Neste mesmo contexto, Erthal (2005) propõe um trabalho referente a produção de um material que auxilie o ensino da corrente alternada ao nível do Ensino Médio. Esse material é constituído de equipamentos demonstrativos que abordam conceitos básicos de eletricidade, incluindo tópicos relacionados a corrente alternada, como a indução eletromagnética, a lei de Lenz e transformadores.

Oliveira (2001) aborda o uso da tecnologia como forma de intermediação tecnológica e suas implicações em um conjunto de relações, de ações recíprocas, no interior das práticas didático-pedagógicas. Após deliberar sobre a inserção tecnológica nos meios de ensino, Oliveira (2001) apresenta, como uma de suas conclusões principais, que o baixo custo dos recursos tecnológicos e a sua oferta no cenário educacional tem função mais direcionada ao 
consumo do que a intenção de construção da cidadania e respeito aos direitos humanos. No entanto, a própria autora reconhece que a tecnologia envolve novos problemas ligados a questões éticas, de segurança e de propriedade intelectual.

Pretto (2006) debate a respeito da utilização do computador como extensão das capacidades cognitivas humanas, beneficiando o pensar, o criar e o memorizar e ressalta que as novas tecnologias passam a operar como uma extensão dos sentidos do homem, atuando com suas ideias. Isso implica que as máquinas não mais estão a serviço do homem, mas também com ele interagem, formando um conjunto homem-máquina pleno de significado.

Guerrero (2010) apresenta um estudo baseado no sistema educacional mexicano, imerso em uma série de decisões políticas orientadas a reformar a educação básica. Esta reforma enfatiza, também, a necessidade de transformação das práticas docentes com o objetivo de tornar os estudantes parte das mudanças tecnológicas que caracterizam as sociedades atuais. $\mathrm{O}$ autor observa que, no México, tem se dado prioridade ao aparelhamento de instituições com equipamentos e programas, mas não se tem documentado mudanças profundas nas formas de ensino, sendo que as modificações continuam sendo superficiais. Isto implica que se modificam os procedimentos com a finalidade de se incorporar as TIC às rotinas de aula, mas não ocorrem variações nos processos de aprendizagem. Tomou-se, não apenas no México, mas em outros países, como verdadeira a crença de que a mera presença de computadores nas salas de aula é sinal de bem-estar e progresso mas, na realidade, isto ocasiona pouca evolução. Guerrero (2010) conduziu um estudo em quatro escolas no México a fim de verificar o andamento da implementação das novas políticas públicas adotadas naquele país, sendo o uso de recursos de tecnologias aplicadas a metodologias educacionais em sala de aula. Através das observações, Guerrero (2010) concluiu que a tecnologia usada em sala de aula pode provocar grandes mudanças nas metodologias de ensino, mas é necessário, ao docente compreender como empregar estes recursos para a prática de ensino, de forma satisfatória. Verifica-se que as TIC podem ser ferramentas poderosas para a construção de situações educativas e para a construção de uma equidade sustentável, assim como de novas opções educacionais. No entanto, é requerido um conhecimento profundo de práticas escolares estáveis e profundamente arraigadas, as quais se desejam modificar para a inclusão adequada dos recursos tecnológicos, bem como as condições, que permitam esta transformação. Da mesma forma, os professores necessitam conhecer e compreender com a mesma profundidade os alcances, limites e potencialidade das ferramentas digitais.

Kenski (1998) faz uma análise das novas tecnologias do ponto de vista do redimensionamento do espaço e do tempo e os impactos sobre o trabalho docente. É reconhecido que a tecnologia reestrutura profundamente a consciência e a memória, impondo novas ordens nas formas tradicionais de compreender e de agir sobre o mundo. Estas tecnologias fixam lembranças acerca de fatos concretos, bem como derrubam barreiras entre acontecimentos reais e ficção. Além disso, de forma coletiva, as novas tecnologias oferecem perspectivas sem precedentes, ao desenvolvimento. A autora reconhece que a inserção tecnológica promove um rompimento com o ambiente escolar, isto é, a escola, diferente de como era antigamente, não é mais o espaço exclusivo para a ação de aprender. Contemporaneamente, as pessoas estão permanentemente aprendendo, devido à superexposição a que estão submetidas - como exemplo, o acesso à internet e à televisão. Um dos principais problemas enfrentados pelos professores recai na baixa qualidade dos programas educacionais existentes e introduzidos como pacotes pedagógicos. Isto se deve a problemas relacionados ao processo de desenvolvimento destas ferramentas computacionais e a falta de participação de educadores neste processo. Uma das principais observações da autora a respeito da utilização de tecnologias em sala de aula recai sobre o domínio das tecnologias educativas pelos professores, garantindo-lhes segurança para que, com 34 
conhecimento de causa possam se sobrepor às imposições sociopolíticas das invasões tecnológicas indiscriminadas às salas de aula. Criticamente, os professores vão poder aceitálas ou rejeitá-las em suas práticas docentes, tirando o melhor proveito dessas ferramentas para auxiliar o ensino no momento adequado.

Alves (2003) faz uma análise da inserção das tecnologias na cultura e no cotidiano escolar. Neste trabalho, Alves (2003) demonstra como os recursos tecnológicos modificam o contexto sociocultural em uma escola, bem como seu impacto sobre a relação aprenderensinar existente entre professores e alunos. Ao procurar utilizar diferenciadas ferramentas de ensino-aprendizagem, o professor também deve levar em consideração as modificações nos padrões comportamentais até então existentes.

Cuban (2001) busca apresentar resultados que explicam as dificuldades e desafios que os professores enfrentam quando se dota de máquinas as suas escolas, sem acompanhar esta distribuição de equipamento com oportunidades de formação. Documentou-se que somente a presença de computadores não basta para modificar as práticas, pois quando os professores adotam as inovações tecnológicas, em geral, tendem a manter mais do que alterar as práticas existentes nas salas de aula. Assim, a apropriação das tecnologias é um assunto muito mais complexo que não depende somente da presença física das mesmas, mas de múltiplos fatores, dentre eles, a disponibilidade da máquina e mediadores que auxiliem o docente no processo.

\section{Metodologia}

A partir das observações apresentadas pelas referências bibliográficas, torna-se necessário, portanto, definir como utilizar de forma eficaz ferramentas tecnológicas auxiliares para o ensino de diversas disciplinas. Neste contexto, este trabalho busca estudar, como elemento balizador, formas de introduzir aos alunos da disciplina de Eletrotécnica-II do curso Técnico em Eletromecânica do Colégio Técnico Industrial de Santa Maria (CTISM) os conhecimentos necessários e pertinentes ao tópico Corrente Alternada por meio de recursos transmidiáticos de interatividade via software mídia ilustrativa. Busca-se compreender como o professor pode se orientar no quesito de como utilizar estes recursos de forma adequada para o ensino deste tópico, de maneira adequada às suas necessidades docentes.

Decorrente da questão de pesquisa tem-se como hipótese geral a possibilidade de utilizar de forma adequada recursos de mídia tecnológica de tal forma que sua aplicação, isolada ou integrada, favoreça o processo de ensino-aprendizagem do tópico referente às correntes alternadas pertinente à disciplina de Eletrotécnica.

O presente estudo propõe, então, analisar alguns dos múltiplos recursos tecnológicos de ensino para a avaliação da potencialidade explanativa do tópico correntes senoidais na disciplina de Eletrotécnica, pertinente do currículo de cursos profissionalizantes de eletricidade. Neste conjunto, procura-se (1) avaliar a adequação das ferramentas de ensino utilizadas até então para a percepção dos alunos iniciantes no tópico correntes alternadas senoidais, (2) verificar o impacto da introdução de novas técnicas/ferramentas no ensino do tópico abordado e (3) observar o processo de adaptação do professor e dos estudantes às novas ferramentas/metodologias introduzidas com o uso de recursos transmidiáticos.

Este trabalho, classificado como uma pesquisa qualitativa aproxima-se do estudo de caso por meio de observações como método de abordagem.

Uma vez que esta pesquisa foi conduzida sobre uma turma do curso de Eletrotécnica as avaliações acima apresentadas se darão ao longo das aulas, por meio de discussões em sala de aula com o grupo a ser observado. Optou-se por não aplicarem-se técnicas avaliativas mais invasivas para aferição da progressão do aprendizado estudantil em virtude de evitarem-se 
conflitos com a metodologia de ensino do professor titular da disciplina bem como não promover expectativas nos alunos, que tendem nos cursos de ciências exatas, a condicionar quaisquer elementos investigativos como recompensa sobre a avaliação curricular "oficial", aplicada pelo professor titular da disciplina. Além disso, considerou-se que, devido ao tempo reduzido para a realização das atividades de estágio, ao longo do qual esta pesquisa se deu, quaisquer trabalhos aplicados, externos aos planejamentos originais do professor titular, poderiam causar perturbações e interferências no andamento da disciplina que porventura iriam destoar dos avanços até então alcançados. Portanto, as observações são baseadas em questionamentos e discussões realizadas em sala de aula, embasadas em conhecimento prévio a respeito do conteúdo a ser ministrado e de experiências anteriores, considerando as dúvidas mais comuns entre os estudantes.

As aulas foram estruturadas de acordo com a proposição de organização didática de Abegg e De Bastos (2005), por ser considerada como uma forma eficaz para o estabelecimento de uma metodologia adequada às observações acima citadas. Ao todo, foram realizados oito encontros de duas horas-aula cada, ao longo de quatro semanas. A turma está com 23 alunos e iniciou novo currículo de eletrotécnica subsequente (que agora é semestral), $80 \%$ da turma trabalha durante o dia e estuda a noite, a faixa etária varia, aproximadamente em torno de 23 anos (a maioria) e as exceções são três alunos acima de 40 anos.

Três ferramentas de mídia foram usadas como ferramentas a serem apresentadas aos alunos. A primeira refere-se a um vídeo disponível no site YouTube.com (2007), conforme apresentado na figura 1. Esta primeira ferramenta foi usada como vídeo ilustrativo em sala de aula.

A segunda ferramenta utilizada trata-se de um aplicativo, em JAVA ${ }^{\mathrm{TM}}$, disponibilizado on-line por Carvalho (2010). Este aplicativo (Figura 2) permite, ao professor, manipular algumas características de um gerador elementar de corrente alternada. Esta liberdade na manipulação das grandezas favorece a revisão de conceitos previamente estudados a respeito de eletromagnetismo, na disciplina de eletrotécnica. Além disso, a exposição dos princípios de operação de um gerador elementar favorecem uma melhor contextualização a respeito do aspecto prático da atividade profissionalizante, aproximando o aluno das reais necessidades da disciplina para sua carreira profissional.

Figura 1 - Vídeo instrucional sobre corrente alternada

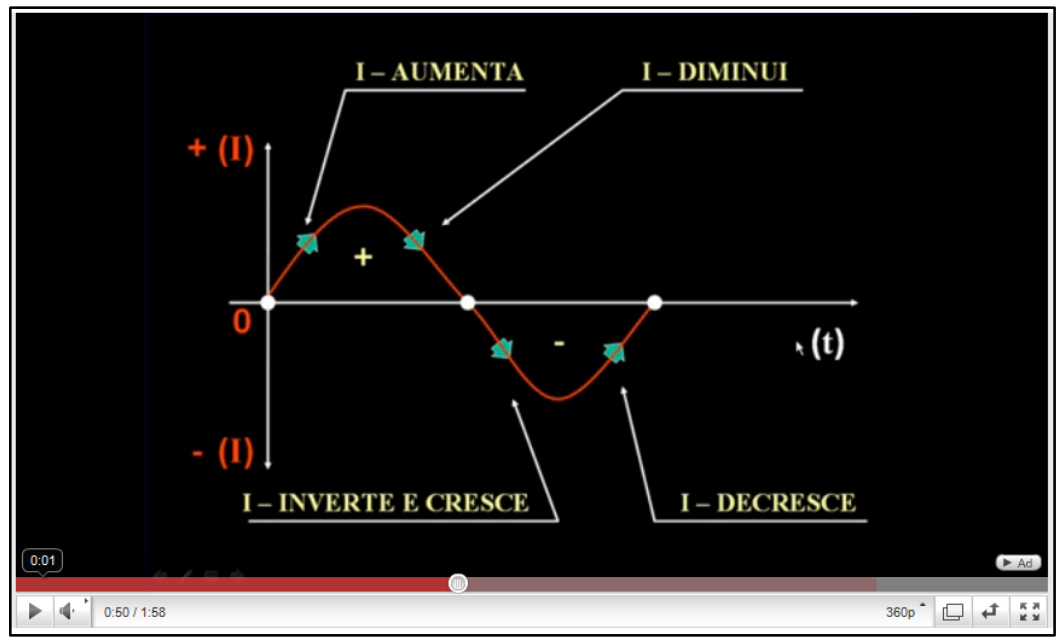

Fonte: YouTube.com (2007). 
Figura 2 - Aplicativo em JAVA ${ }^{\mathrm{TM}}$ para demonstração da geração de corrente alternada

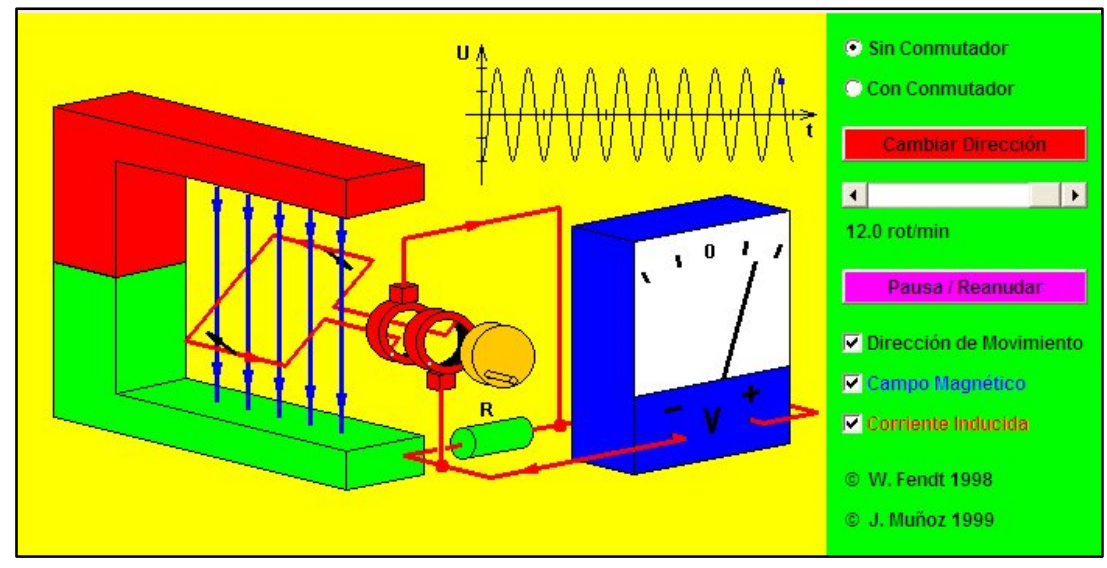

Fonte: Carvalho (2010).

A terceira ferramenta utilizada trata-se de um programa de simulação comercial,

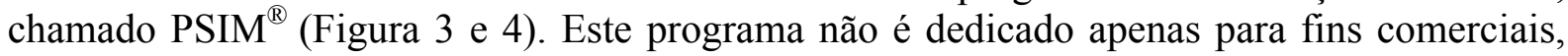
apesar de o fabricante disponibilizar uma versão estudantil (ou de demonstração) para download em seu website, podendo ser usado em outras situações. Aqui, os alunos foram ensinados a manipular esta ferramenta de tal forma que fosse possível que os mesmos apliquem-na, posteriormente, em outras atividades na disciplina de eletrotécnica, bem como em outras disciplinas. Como se trata de uma ferramenta computacional mais ampla, a mesma pode ser utilizada em disciplinas que abordam eletrônica, máquinas elétricas, fontes alternativas, dentre outras. Isso demonstra o caráter interdisciplinar da ferramenta.

Figura 3 - Interface de simulação

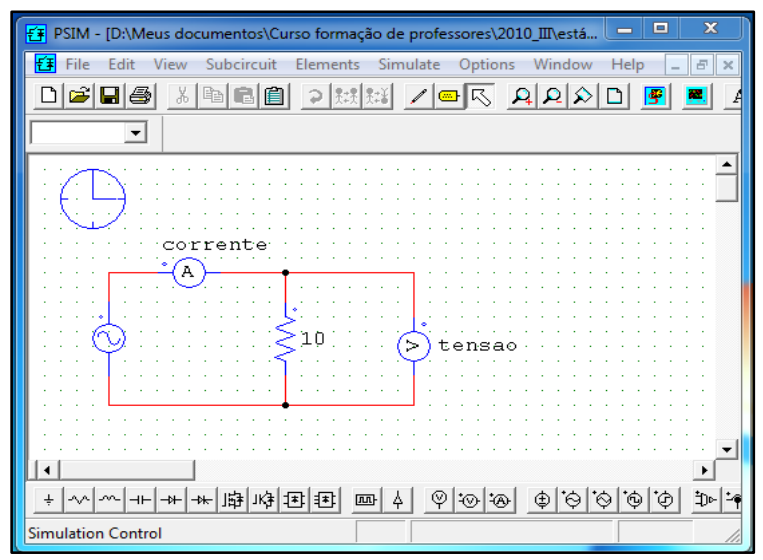

Fonte: PSIM ${ }^{\circledR}, 2010$ 
Figura 4 - Interface de visualização dos resultados

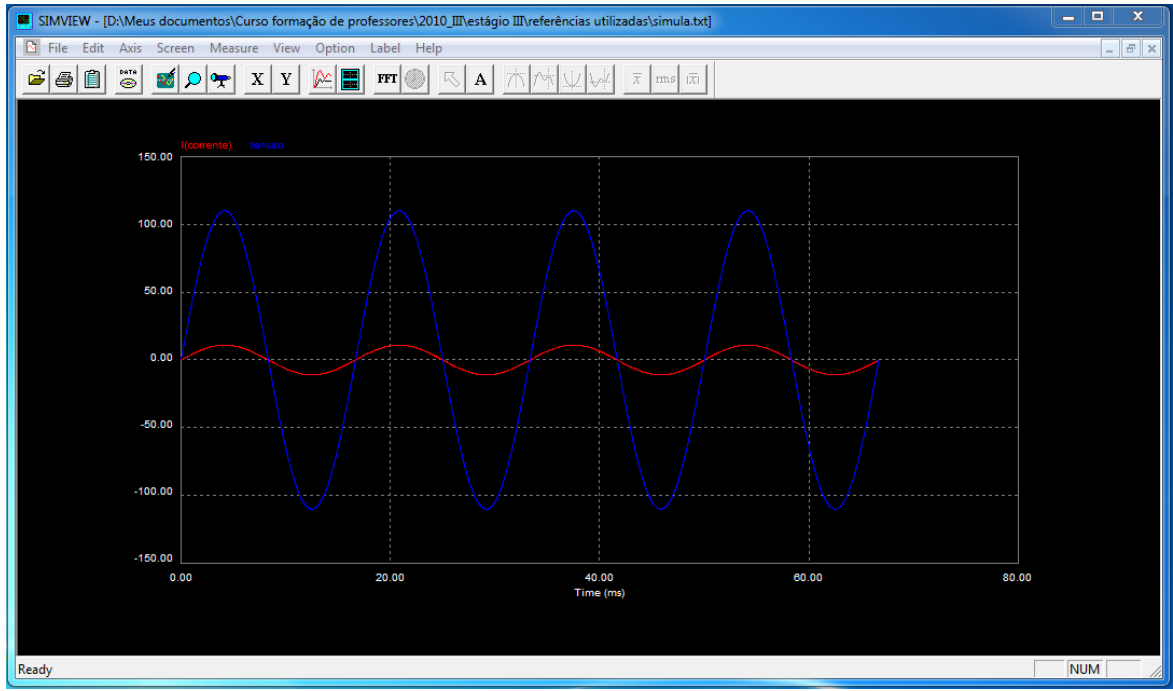

Fonte: PSIM ${ }^{2}, 2010$

\section{Apresentação dos resultados}

A seguir, são fornecidas as principais observações anotadas durante o decorrer do exercício das atividades de docentes sob investigação.

Observa-se que, inicialmente, os alunos apresentam certa dificuldade em visualizar os fenômenos referentes às grandezas senoidais. Em geral, esta dificuldade é esperada, pois os alunos, até este momento, estavam habituados à análise e ao estudo teórico de circuitos em corrente contínua. Normalmente, por meio de experiência prévia com esta cadeira, verifica-se que uma das principais dificuldades dos alunos reflete-se na capacidade de abstração para a compreensão dos fenômenos envolvidos com grandezas senoidais. Por exemplo, um conceito bastante complexo aos alunos iniciantes refere-se ao entendimento do que vem a ser a frequência de um sinal. Eventualmente, a demonstração de frequência pode-se, em sala de aula, ser exemplificada acendendo-se e apagando-se um interruptor de iluminação. Quanto maior o ciclo liga-desliga, maior será a frequência do evento. A partir daí, é possível fazer uma tradução teórica do fenômeno. A visualização gráfica dos conceitos envolvidos, neste primeiro momento é relativamente difícil para o aluno iniciante na disciplina. Para tanto, torna-se necessário lançar mão de ferramentas de mídia adicionais, tais como vídeos e/ou softwares de simulação de circuitos. Portanto, na primeira aula, é realizado um trabalho com os alunos, utilizando a primeira ferramenta - o vídeo introdutório, disponibilizado no YouTube.com (2007). A partir de então se conduz uma discussão mais aprofundada sobre o tópico, incluindo-se uma contextualização do tema.

A partir de experiência prévia com a cadeira, nota-se que é necessário lançar mão de recursos adicionais para demonstrar os princípios de geração em corrente alternada (CA) propriamente ditos. O aplicativo em JAVA ${ }^{\mathrm{TM}}$ de Carvalho (2010) utilizado nesta aula tem esta potencialidade. Por meio de uma interface de utilização simplificada, o pode-se manipular um gerador CA elementar. Observou-se que, por meio de indagações em sala de aula, a visualização da produção de energia em corrente alternada estava difusa entre os alunos. Após a apresentação da ferramenta e o acesso dos alunos a mesma, foi possível aos estudantes o estabelecimento das noções básicas necessárias aos processos intrínsecos de produção de energia em corrente alternada. Assim, a capacidade de abstração dos alunos a respeito do tema foi alterada no sentido de ampliar as percepções sobre o conteúdo. 
Observou-se, de forma subjetiva, uma aceitação positiva, por parte dos estudantes, da ferramenta utilizada.

Nesta aula, foram introduzidas noções de medição de grandezas elétricas em CA. Este tópico é importante por apresentar aos estudantes os equipamentos de medição em CA, análogos aos equipamentos utilizados em CC. Também foi possível introduzir aos estudantes as diferenças entre valores médios, eficazes e de pico de grandezas senoidais. Por meio de experiência docente prévia, na área, pode-se dizer que estes conceitos, em geral causam algumas dúvidas, com respeito a sua introdução inicial. De forma natural, estas dúvidas passam a ser esclarecidas no decorrer da disciplina e com a realização de atividades adicionais (discussões, exercícios, dentre outros). Neste momento, a disciplina de Eletrotécnica apresenta fortes vínculos com outra disciplina, chamada de Medidas Elétricas. Portanto, contextualiza-se ambas as disciplinas, estabelecendo-se laços com a vida profissional. Observou-se que os alunos demonstraram bastante interesse no uso e manuseio dos equipamentos de medição em sala de aula. Este interesse é bastante explorado, paralela e posteriormente em outras cadeiras do curso.

Observou-se uma boa receptividade dos alunos ao software. Em parte, isto se deve a simplicidade da plataforma e a intuitividade no uso do programa. Afirmações teóricas realizadas em aulas anteriores foram passíveis de comprovação por meio de simulações. Além disso, os alunos conseguiram se apoderar de uma ferramenta adequada aos seus estudos, que permite a construção de circuitos elétricos em computador sem a necessidade de efetivamente construí-los na prática, tornando o processo de análise mais imediato e seguro.

Foi observado que a sistemática de cálculos e aplicações das técnicas de análise de malhas e nós de Kirchoff eram lembrados de forma adequada. O docente responsável pela disciplina introduziu estes conhecimentos de forma ampla e adequada no decorrer da disciplina Eletrotécnica I, permitindo uma rápida adaptação das teorias vistas em circuitos CC às necessidades dos cálculos em $\mathrm{CA}$.

Observa-se que, de forma similar a aula onde o software foi introduzido, a aceitação dos alunos foi bastante positiva. A percepção a respeito da análise de circuitos e os efeitos das leis das malhas e dos nós de Kirchoff foram expandidos com o uso da ferramenta PSIM ${ }^{\circledR}$. Neste sentido, as observações realizadas são bastante similares com aquelas apresentadas para a $4^{\text {a }}$ aula.

A análise de circuitos RLC em corrente alternada geralmente causa dúvidas entre os alunos durante a sua introdução. Isso se dá pelo fato de o aluno nem sempre conseguir discorrer de forma total acerca da amplitude de fundamentos em que se baseia o conceito de impedância. Na disciplina de Eletrotécnica II, após o impacto inicial, de forma gradual e progressiva os alunos se mostraram mais participativos e interessados a respeito do tema. Em geral, este interesse é normal, devido ao fato de o termo "impedância" de um equipamento eletroeletrônico ser bastante comum em manuais e apostilas. Assim, a curiosidade dos alunos é despertada. Isso permite, por meio da contextualização com a cultura geral do aluno, introduzir e aprofundar o conhecimento pertinente ao tema.

Observou-se que, de forma similar as aulas anteriores, onde foi utilizado o PSIM $^{\circledR}$ para validação dos resultados, os alunos se sentiram mais confortáveis no que tange ao questionamento a respeito do trato de circuitos elétricos em CA.

\section{Análise dos Resultados}


Por meio das observações registradas no decorrer das aulas, pode-se dizer que os resultados obtidos por meio da aplicação das ferramentas multimídia nas aulas de eletrotécnica demonstraram ter resultados positivos.

Como um dos objetivos refere-se adequação das ferramentas de ensino utilizadas até então para a percepção dos alunos iniciantes no tópico correntes alternadas senoidais, pode-se inferir que, do ponto de vista de aprendizado, o acréscimo introduzido por estas ferramentas mostrou-se bastante satisfatório, uma vez que as mesmas apresentam-se como um artifício útil para aplicação em sala de aula, tanto como material de apoio para o professor (caso das ferramentas de vídeo e em $\mathrm{JAVA}^{\mathrm{TM}}$ ) quanto como elemento de interatividade para o aluno, isto é, por meio de simuladores interativos (caso do simulador $\operatorname{PSIM}^{\circledR}$ ).

Através de conhecimento previamente adquirido em outras oportunidades com a mesma disciplina, foi possível verificar o impacto da introdução de novas técnicas/ferramentas no ensino do tópico abordado. Turmas anteriores, as quais os professores não dispunham de tais ferramentas auxiliares para o curso de suas aulas, demonstravam, geralmente, ter uma velocidade de aprendizado um pouco mais lenta do que a turma observada durante os trabalhos investigativos conduzidos neste artigo. Este fato não remete a problemas cognitivos ou similares, mas a um aspecto pouco mais sutil: a visualização imediata dos resultados apresentados à turma, por meio dos recursos, favorece a compreensão do tópico abordado de forma mais rápida com relação ao que ocorria antigamente. Em épocas anteriores, sem o auxílio de recursos tecnológicos, era exigido dos estudantes um nível mais intenso no que se refere à capacidade de abstração do tema. Além disso, uma vez que a maioria do processamento de cálculo era conduzido de forma manual e com ferramentas disponíveis à época, a necessidade massiva de exercícios de aprendizado era muito mais intensa e, frequentemente ineficaz, uma vez que o estudante sofria em decorrência dos cálculos onerosos, requeridos para atingir os cálculos finais. Isto significa que, atualmente, com o uso de ferramentas de mídia, o processo de nivelamento em torno da capacidade de discussão aluno-professor dos tópicos abordados é muito mais acentuado, isto é, os alunos se mostram muito mais hábeis para a discussão com o professor a respeito do tópico em termos de níveis de conhecimento.

Quanto ao processo de adaptação do professor e dos estudantes às novas ferramentas/metodologias introduzidas com o uso de recursos transmidiáticos, pode-se dizer que, no contexto observado, as ferramentas usadas não demonstram dificuldades, o que não onera, de forma não tornar extenuante a atividade de planejamento das aulas do professor. $\mathrm{O}$ significado disto é que, o professor pode abraçar o uso destas ferramentas com baixo impacto para a sua metodologia original. Ao contrário, os ganhos se mostram positivos, pois, uma vez que os recursos são aplicados, os alunos conseguem se apropriar dos conhecimentos básicos necessários ao entendimento do conteúdo abordado. Sendo assim, o professor ganha "tempo extra" em suas aulas para trabalhar outros tópicos pertinentes ao conteúdo e criar outras formas de discussão adicionais que porventura possam se mostrar importantes ao aprendizado e ao cotidiano profissional dos alunos.

\section{Conclusões}

A aplicação de recursos de mídia em sala de aula se mostrou bastante positivo, no contexto avaliado durante esta investigação. De acordo com as referências estudadas, observase que a tecnologia possibilita mudanças. No entanto, para o caso analisado o que se observou e descreveu como mudanças não são atividades radicalmente novas. As mudanças instituídas se observam em pequenas modificações nas aulas que correspondem a compreensão das potencialidades representativas dos recursos empregados por alunos e professores em 
conjunto com a articulação simultânea de vários significados. É importante observar que se documentaram mudanças na maneira de se aplicar e operar os recursos de mídia no que concerne a metodologia abordada pelo professor.

O professor observado continua fazendo com tecnologias eletrônicas parte do que fazia sem as mesmas. De forma geral, sua prática não se modificou radicalmente pela inserção de computadores em sala de aula. Isto é um fato encarado como positivo, tendo em vista que, para a grande parte dos professores, alterações críticas em suas metodologias podem ser encaradas como um fator problemático. Assim, conclui-se que uma das melhores maneiras de se introduzir recursos de mídia em sala de aula, para muitos docentes, é por meio de metodologias não intrusivas e gradualmente sutis em sua aplicação.

No caso dos estudantes, pequenas modificações se observaram com a possibilidade de se usarem as potencialidades dos recursos. Estas modificações, em parte, são pequenas, mas são bons exemplos de como os alunos compreendem os benefícios ou potenciais oferecidos pelo computador.

Apesar de os resultados serem, em uma análise imediata, considerados como positivos, são requeridas ainda investigações adicionais para detectar se estas técnicas resultariam nas mesmas consequências em outras instituições. Além disso, seria interessante realizar um acompanhamento da turma estudada em um prazo mais longo, a fim de se verificar se os conhecimentos adquiridos com estas metodologias seriam conduzidos de forma adequada ao longo da vida profissional dos estudantes do curso técnico avaliado.

\section{Referências}

ABEGG, I. \& DE BASTOS, F. da P. (2005). Fundamentos para uma prática de ensinoinvestigativa em Ciências Naturais e suas tecnologias: Exemplar de uma experiência em séries iniciais. Revista Electrónica de Enseñanza de las Ciencias, 4 (3), 1-15. $\begin{array}{lllll}\text { Recuperado em } & 19 & \text { julho, } & \end{array}$ http://reec.uvigo.es/REEC/spanish/REEC_older_es.htm.

ALVES, N. (2003). Cultura e cotidiano escolar. Revista Brasileira de Educação, Maio/Jun/Jul/Ago (23), 62-74. Recuperado em 02 maio, 2012, de http://dx.doi.org/10.1590/S1413-24782003000200005.

CARVALHO, V. P. (2010). Gerador elétrico. Recuperado em 21 de setembro de 2010, de http://www.if.ufrgs.br/tex/fis01043/20011/Vasco/index.html.

COSTA, G. \& CATUNDA, T. (2009). Circuitos elétricos segundo a abordagem de demonstrações investigativas: resultados preliminares. Recuperado em 24 de maio de 2010, de http://www.sbf1.sbfisica.org.br/eventos/snef/xviii/sys/resumos/T0198-1.pdf.

CUBAN, L.; KIRKPATRICK, H.; E PECK, C.; (2001). High Access and Low Use of Technologies in High School Classrooms: Explaining an Apparent Paradox. American Educational Research Journal, 38, (4), pp. 813-834.

ERTHAL, J.; \& Gaspar, A. (2005. novembro). Construção de atividades experimentais de demonstração com material de baixo custo para o ensino de tópicos relacionados à corrente alternada ao nível do ensino médio. Anais XVI Simpósio Nacional de Ensino de Física, Maresias, SP, Brasil, 16. 
Ferreira, J.; Lopes, R. et al. (2009, junho). A apresentação de circuitos elétricos e seus respectivos conceitos da Física através da experimentação real e virtual. Anais I Simpósio Nacional de Ensino de Ciência e Tecnologia, Curitiba, PR, Brasil, 1.

GUERRERO, I. \& KALMAN, J. (2010). La inserción de la tecnología en el aula: estabilidad y procesos instituyentes en la práctica docente. Revista Brasileira de Educação, 15(44), p. 213-405.

KENSKI, V. M. (1998). Novas tecnologias: o redimensionamento do espaço e do tempo e os impactos no trabalho docente. Revista Brasileira de Educação, Mai/Jun/Jul/Ago, (8).

OLIVEIRA, M. R. N. S. (2001). Do mito da tecnologia ao paradigma tecnológico: a mediação tecnológica nas práticas didático-pedagógicas. Revista Brasileira de Educação, Set/Out/Nov/Dez, (18).

PRETTO, N. \& PINTO, C. da C. (2006). Tecnologias e novas educações. Revista Brasileira de Educação, 11 (31) jan./abr. 2006.

PSIM $^{\circledR}$. PSIM ${ }^{\circledR}$ : From Design to Simulation and Implementation. Recuperado em 29 de setembro de 2010, de http://www.powersimtech.com.

YOUTUBE.COM. Curso de Eletrônica: Corrente Alternada. Recuperado em 13 de setembro de 2010, de http://www.youtube.com/watch?v=pT_DEQOTh4I. 